\title{
Localised nasal actinic porokeratosis: An independent subtype of porokeratosis?
}

\author{
Nidhi Sharma, Yukti Aggarwal, Suresh Kumar Malhotra, Kuldeep Singh Chahal
}

Departments of Dermatology and Pathology, Government Medical College, Amritsar, Punjab, India

Corresponding author: Dr. Nidhi Sharma, E-mail: drnidhisharma@hotmail.com

\begin{abstract}
Porokeratosis (PK) are a group of keratinizing disorders clinically characterized by atrophic plaques with peripheral hyperkeratotic ridge which gradually spread in a centrifugal manner. The sites of predilection are trunk or extremities and facial lesions are rarely reported. We report a sporadic adult-onset case of porokeratosis of a 20 year old female with a solitary, asymptomatic, persistent classical plaque confined to the ala of nose. On reviewing the literature, nasal and perinasal area has been found to be exclusively involved in many cases of facial porokeratosis. Such cases have unique yet common epidemiological and clinical profile thereby deserving a separate category while being classified.
\end{abstract}

Key words: Porokeratosis; Nasal alae; Localized; Solar; Non-familial

\section{INTRODUCTION}

Porokeratosis (PK) is an epidermal keratinizing disorder, characterized clinically by distinct, indolently evolving, annular plaques with atrophic center and irregular, peripheral, elevated hyperkeratotic ridge as well as histologically by the cornoid lamella [1].

The etiopathogenesis of PK is complex and has been broadly attributed to the peripheral expansion of abnormal and mutant clone of parakeratotic keratinocytes [2]. The attributing risk factors for clonal proliferation may be intrinsic i.e. genetically determined or extrinsic factors like immunosuppression, immunodeficiency (AIDS), ultraviolet radiation, infections, mechanical trauma, drugs (thiazide diuretics), hematological malignancies, autoimmune diseases, and occupational exposure to benzene etc [3].

Clinically, six distinct types of $\mathrm{PK}$ are well recognized i.e. PK of Mibelli (PM); disseminated superficial actinic PK (DSAP); disseminated superficial PK (DSP); PK palmaris et plantaris disseminate (PPPD); punctate PK and linear PK [4]. The usual pattern of inheritance is autosomal dominant but at times it may be sporadic. A few of these subtypes exhibit propensity for malignant transformation as conversion into squamous cell carcinoma, Bowen disease and basal cell carcinoma has been described in $6.8-11.0 \%$ cases of PK [5].

Common sites of predilection are trunk and extremities although sporadic cases of involvement of palms and soles, face, oral mucosa, lips have been reported [5]. The present study highlights the high incidence of nasal PK among the reported cases in the world literature which is clinically and epidemiologically distinct from other types of PK.

\section{CASE REPORT}

A twenty year old female patient presented with persistent, asymptomatic plaque over nose since two years. It started as a small papule which slowly progressed in size in a centrifugal manner. Photosensitivity was present. Past medical and family history was nonsignificant. On clinical examination, there was a single plaque of size $1 * 1.5 \mathrm{~cm}$ confined to the right alae of nose (Fig. 1). There was atrophy in the center of the lesion and margins were hyperkeratotic and peripherally raised to a height of $3 \mathrm{~mm}$ with perimarginal fissure. Otherwise general physical and systemic examination 
was unremarkable. Routine laboratory investigations were within normal limits. Viral markers and ELISA for HIV-1, 2 were non-reactive. The differential diagnosis of discoid lupus erythematosus, PK, basal cell carcinoma, lupus vulgaris and sarcoidosis were considered. An incisional skin biopsy revealed parakeratotic invaginations in the epidermis (Fig. 2) consistent with the diagnosis of PK.

\section{DISCUSSION}

Although, PK was first described by Mibelli in 1893, a case of facial PK was first reported in 1979 by Mehregan. He reported that 197 cases out of 165,000 consecutive skin biopsy specimens verified histologically for $\mathrm{PK}$, of which only seven patients had primary facial lesions (3.5\%) [6]. On reviewing the literature, 49 cases of Facial/Nasal PK, with variable categorization have been identified. Their demographic and clinical features are shown in Table 1.

As evident from the table, there was exclusive involvement of nose and the perinasal area in 26 cases

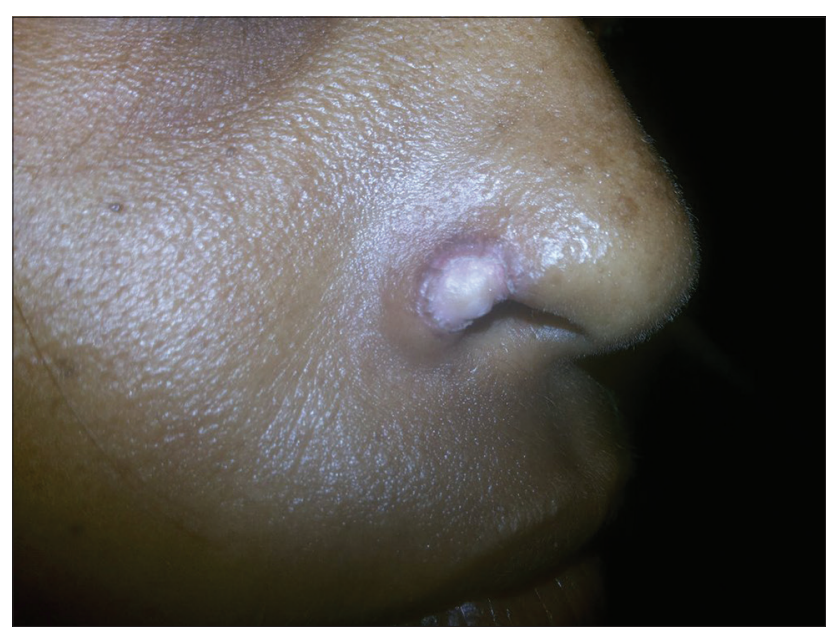

Figure 1: A single plaque of size $1 * 1.5 \mathrm{~cm}$ confined to the right alae of nose with central atrophy and peripherally raised hyperkeratotic margins.

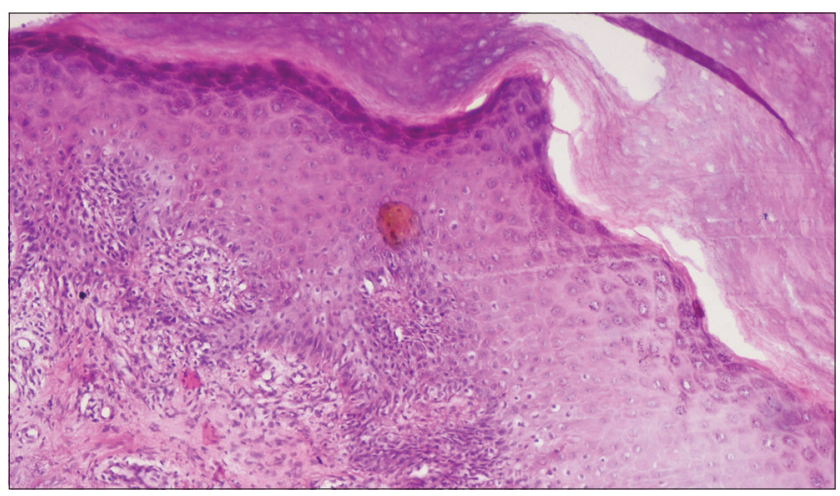

Figure 2: Parakeratotic invaginations in the epidermis. (H\&E 1000x).

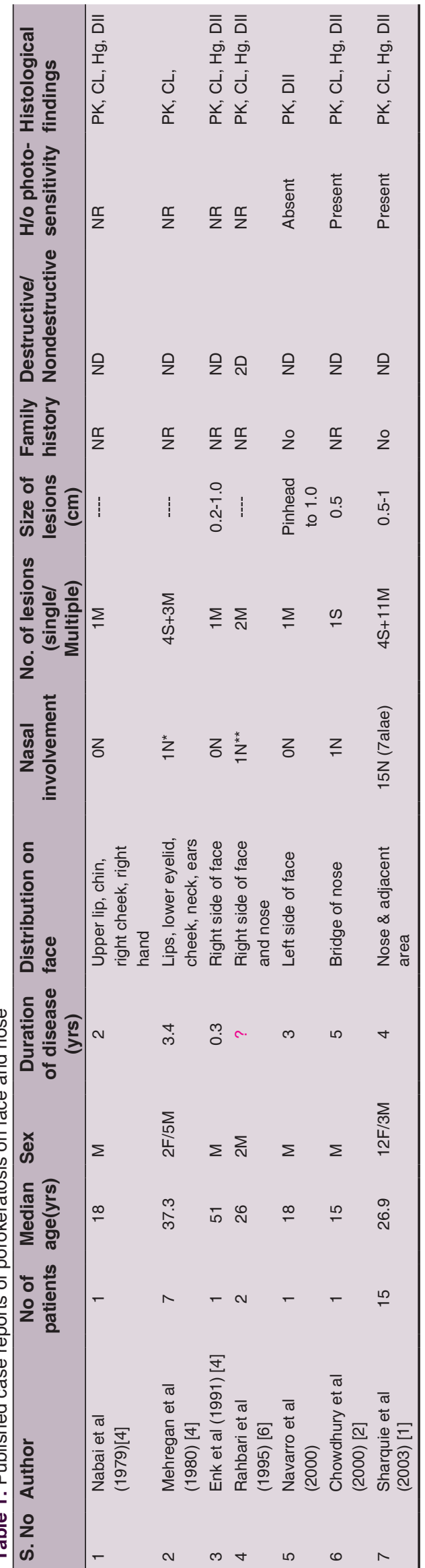




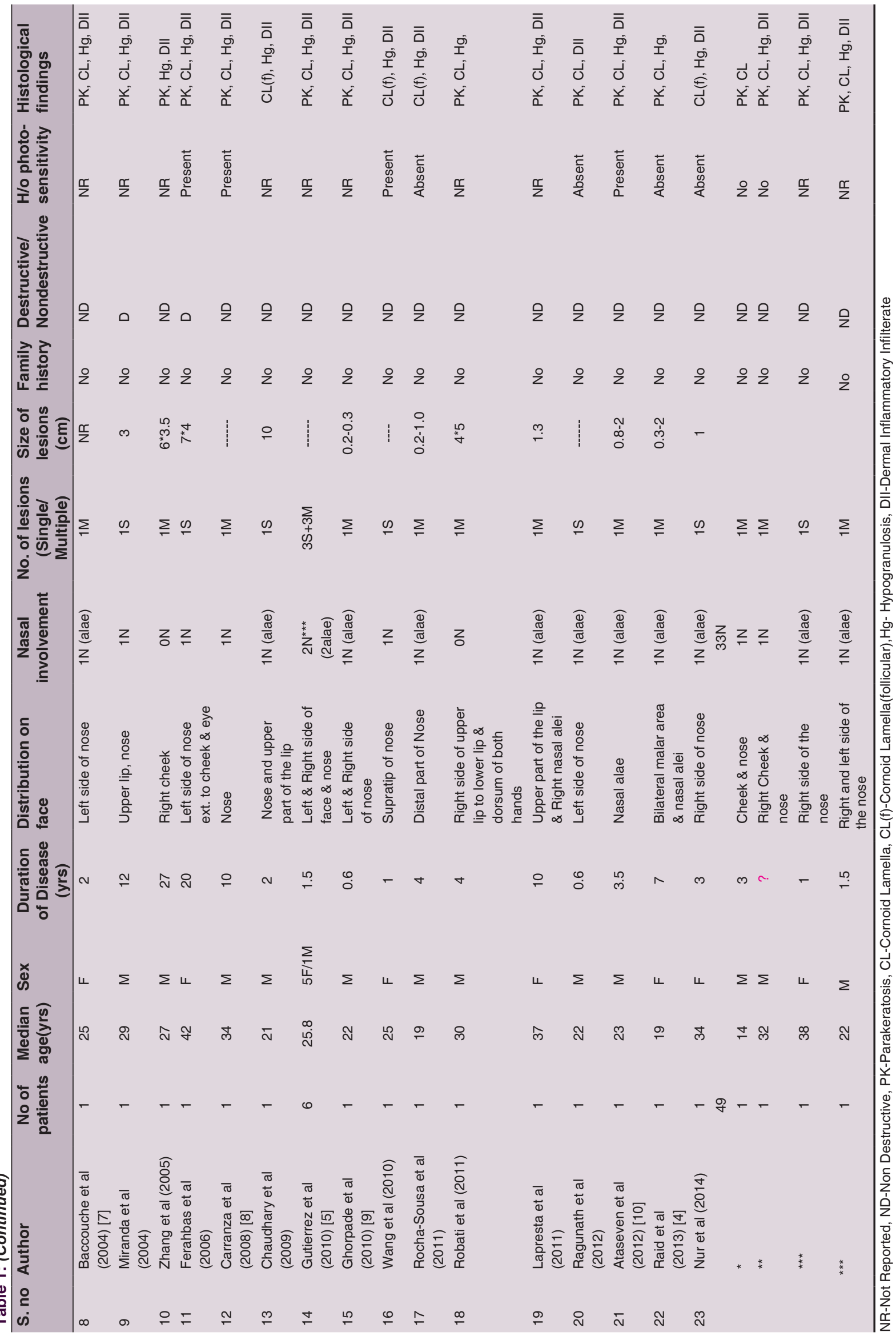


out of 49 and yet another 7 cases of nasal PK had additional involvement of cheek, lips and eye. Among these 26 cases, there were 16 females and 10 males. Their ages ranged from $15-38$ years with mean age being $25.49 \pm 6.73 \mathrm{SD}$.

The duration of the disease ranged from 6 months to 10 years with a mean \pm SD of $3.02 \pm 2.66$ years. The size ranged from $0.2-2 \mathrm{~cm}$ in the reported cases. The lesions were solitary in 9 cases and multiple in 17 cases.

19 out of 26 cases of nasal PK had a definite history of photosensitivity which may have acted as an aggravating factor. But in 4 cases, photosensitivity was not reported while in 3 cases it was found to be altogether absent.

The family history was noticeably negative in all these patients. None of these patients reported any kind of destructive change supervening over primary lesions of PK. The histopathological hallmark of PK, the cornoid lamella was observed in all the cases. The granular layer was absent under the cornoid lamella and perivascular lymphoid infiltrate in the dermis was noted in most of the cases.

Clinically, our case did not fit completely into any of the six clinical variants of PK. Interestingly, this case had gross similarity to the single largest published series (12 female and 3 male patients) [1] and the subsequent individual case reports of nasal PK [5,7-9].

In most of these publications, similar lesions were not reported in preceding or succeeding generations, so genetics probably played no role in the etiopathogenesis of this entity. In almost all the case reports, history of photosensitivity was present thereby implicating sunlight or artificial ultraviolet light either in induction or exacerbation of cutaneous lesions over nose. UVexposure causes $\mathrm{p} 53$ mutations by inducing thymidine dimers thereby causing local immunosuppression. Although face, neck, and limbs all are exposed to sunlight, in these cases a few small sized lesions of $\mathrm{PK}$ are limited to the nose and adjacent perinasal area only. Thus, this subtype differs from all other types of PK except DSAP in relation to sensitivity to sunlight.

In DSAP, $15 \%$ of patients with facial lesions have lesions on other sun-exposed areas of the body [1].
DSAP is inherited as an autosomal trait with the gene locus identified at chromosome $12 \mathrm{q}$ and $15 \mathrm{q}$ [4]. The lesions begin to develop in the teenagers of affected families, with penetrance nearly complete by the third and fourth decades of life.

This variant neither exhibits any inheritable pattern nor any pre-malignant potential. Thus the actinic damage seems to cause limited injury, thereby resulting in localized form of PK.

This case is reported due to exclusive location of PK on nasal alae which owing to specific morphology, distribution and clinical course may be classified into separate category of "localized nasal actinic Porokeratosis". As more and more similar cases will be reported, the existence of this entity will be further clarified.

\section{REFERENCES}

1. Sharquie KE, Al-Baghdady BA. Solar facial porokeratosis. J Dermatol. 2003;30:216-21.

2. Emine N Rifaioğlu, Gülzade Ö. Follicular Porokeratosis at Alae Nasi: A Case Report and Short Review of Literature. Indian J Dermatol. 2014;59:398-400.

3. Sertznig P, von Felbert V, Megahed M. Porokeratosis: present concepts. J Eur Acad Dermatol Venereol. 2012;26:404-12.

4. Riad H, Mansour K, Sada HA, Shaika SA, Ansari HA, Mohannadi HA. Disseminated Superficial Actinic Porokeratosis on the Face Treated with Imiquimod 5\% Cream. Case Rep Dermatol. 2013;5:283-9.

5. Gutierrez EL, Galarza C, Ramos W, Tello M, De Paz PC, Bobbio Let al. Facial porokeratosis: A series of six patients. Australas J Dermatol. 2010;51:191-4.

6. Rahbari H, Fazel Z, Mehregan AH. Destructive facial porokeratosis. J Am Acad Dermatol. 1995;33:1049-50.

7. Baccouche D, Denguezli M, Sriha B, Ghariani N, Belajouza C, Nouira R. Depressed keratotic macules on the face. Ann Dermatol Venereol. 2004;131:1002-3.

8. Carranza DC, Haley JC, Chiu M. Facial Porokeratosis. Skinmed. 2008;7:51-2.

9. Ghorpade A. Localized actinic nasal porokeratosis. Clin Exp Dermatol. 2010;35:211-2.

10. Ataseven A, Öztürk P, Dilek N, Küçükosmanoğlu I. Localized actinic nasal porokeratosis: a case report. Acta Dermatol Venerol. 2012;21:79-80.

Copyright by Nidhi Sharma, et al. This is an open access article distributed under the terms of the Creative Commons Attribution License, which permits unrestricted use, distribution, and reproduction in any medium, provided the original author and source are credited.

Source of Support: Nil, Conflict of Interest: None declared. 